\title{
Fruit Ripening in Sour Cherry: Changes in Expression of Genes Encoding Expansins and other Cell-wall-modifying Enzymes
}

\author{
Sang-Dong Yoo, ${ }^{1}$ Zhifang Gao, Claudio Cantini, ${ }^{2}$ Wayne H. Loescher, and Steven van Nocker ${ }^{3}$ \\ Department of Horticulture, Michigan State University, East Lansing, MI 48824-1325
}

Additional Index words. Prunus cerasus, expansin, PME, PEL, XET, fruit ripening, fruit softening

\begin{abstract}
Aвstract. A preliminary understanding of developmental processes among divergent species is essential to evaluate the applicability of information from model species to plants of agricultural importance. In tomato (Lycopersicon esculentum Mill.), where the molecular biology associated with fruit ripening has been studied most extensively, tissue softening is due at least in part to the activity of proteins called expansins, in concert with enzymatic activities that modify the pectin and xyloglucan components of the cell wall. We evaluated the potential for the concerted action of expansins and other cell wall-modifying enzymes during ripening in a highly divergent fruit species, sour cherry (Prunus cerasus L.). We identified a family of four expansin genes that was strongly upregulated at the advent of ripening. Activation of these genes was accompanied by strong upregulation of gene(s) encoding potential pectin methylesterases, pectate lyase(s), and xyloglucan endotransglycosylase(s). Initiation of ripening and gene induction were also associated with a rapid decrease in cell wall weight. These results suggest that expansin and several other distinct activities could be involved in ripeningassociated cell wall modification in cherries.
\end{abstract}

Of the various aspects of fruit quality, firmness is of paramount importance to horticultural industries, as firmness dictates the methods by which fruit can be harvested, packed, transported, and marketed. The cell wall is the major determinant of plant cell strength and structure, and thus is an important effector of tissue firmness. Most studies of tissue firmness have been carried out with tomato (Lycopersicon esculentum Mill.) fruit, and much of this work has focused on characterizing the potential role of specific cell wall-modifying genes in the softening process (reviewed by Brownleader et al., 1999). Cumulative results from experiments with transgenic tomatoes have indicated that some of the most well-studied genes known to act in cell wall modification, such as polygalacturonase (PG), pectin methylesterase (PME), and endo-ß-1,4-glucanase, probably do not have important roles in fruit softening in tomato, at least in the early stages of the process (Brummell, 1999; Brummell and Labavitch, 1997; Giovannoni et al., 1989; Hall et al., 1993; Lashbrook et al., 1998; Tieman and Handa, 1994).

In contrast, these studies have pointed to a critical role for expansins-a recently characterized class of proteins thought to weaken noncovalent interactions between cellulose microfibrils and hemicellulosic components (Cosgrove, 1998; McQueenMason and Cosgrove, 1995). Transgenic fruit in which expression of the ripening-associated expansin LeEXPl was suppressed were significantly firmer (Brummell et al., 1999a). Expression of LeEXP1 RNA can be detected as early as the mature-green stage of tomato fruit development (Brummell et al., 1999b), implying a function at the earliest stages of softening. Rose et al. (1997) suggested that expansins might be important in regulating the accessibility of wall polymers to enzyme action. Brummell et al. (1999a) suggested that LeEXPl acts in fruit softening both

Received for publication 8 May 2002. Accepted for publication 25 Oct. 2002. This work was supported by a grant from the Michigan Agricultural Experiment Station to S.V.N. We thank Bernard Henrissat for assistance with gene classification.

${ }^{1}$ Present address: Department of Molecular Biology, Massachusetts General Hospital, Boston.

${ }^{2}$ Present address: Dipartimento Scienze Ambientali, Università di Siena, Siena, Italy.

${ }^{3}$ Corresponding author; e-mail vannocke@msu.edu. independently, as a modifier of the cellulose-hemicellulose network, and synergistically with pectin (and possibly hemicellulose) depolymerizing enzymes. In addition to expansin, pectate lyase (PEL) likely plays a key role in fruit softening, at least in some species, as transgenic strawberries (Fragaria ananassa Duch.) in which a $P E L$-like gene was suppressed were significantly firmer (Jiménez-Bermúdez et al., 2002).

We are studying the molecular basis for tissue softening in sour cherry (P. cerasus L.) fruit. Development of this fruit differs from that of tomato, strawberry, and many other fruit in several fundamental respects. For example, cherry exhibits a well-characterized, biphasic growth pattern, with softening and other ripening processes coupled with the beginning of the second growth phase (Tukey, 1935). This is distinctly different from tomato, where softening is initiated only after fruit growth has ceased (Brummell and Harpster, 2001). Cherry is a nonclimacteric fruit, in which ethylene does not seem to have an important role in coordinating ripening processes ( $\mathrm{Li}$ et al., 1994), and, unlike some other nonclimacteric fruit such as strawberry, it is a true, ovary-derived fruit. Finally, cherry development occurs very rapidly ( $\approx 55 \mathrm{~d}$ from pollination to fully ripe fruit) in comparison with other tree fruit. Sour cherry is included in the genus Prunus, which includes several other horticulturally important fruit crops. Thus, sour cherry represents a potentially valuable model for the study of fruit tissue softening. The goal of this project was to identify genes encoding expansins and other potential cell-wallmodifying enzymes that may play a key role in fruit softening in sour cherry.

\section{Materials and Methods}

Plant material. 'Montmorency' sour cherry plants were grown under field conditions in East Lansing, Mich. For extraction of RNA, the gynoecium was dissected from flowers at anthesis, or fruit was collected at 4 to 6-d intervals during the course of development. All collections were made in the early evening. Pericarp (skin and fleshy mesocarp) tissues were used for RNA extraction. After dissection, samples were immediately frozen in liquid nitrogen and stored at $-80{ }^{\circ} \mathrm{C}$ until use. 
Cell wall weight determination. Fruit tissues (20 g), exclusive of the pit and seed, were homogenized in $50 \mathrm{~mL} 2$ phenol : 1 acetic acid : 1 water (by volume), and insoluble cell wall material was collected by centrifugation at $12,000 \mathrm{~g}_{\mathrm{n}}$ for $30 \mathrm{~min}$ and lyophilized. Cell wall material was washed twice with $50 \mathrm{~mL}$ of $90 \%$ (v/v) dimethyl sulfoxide, and subsequently three times with $100 \mathrm{~mL}$ of $80 \%$ (v/v) ethanol, lyophilized, further dried in a vacuum oven at $40{ }^{\circ} \mathrm{C}$, and stored over silica gel in a vacuum desiccator. Because of the low yield obtained from individual fruit, 12 to 20 fruit from each developmental stage were pooled for analysis.

NUCLEIC ACIDS EXTRACTION AND GEL-BLOT ANALYSES. DNA was isolated from young leaves using the method of Doyle and Doyle (1990). Total RNA was isolated as described by Hunter and Reid (2001). Poly(A)-enriched RNA was isolated from total RNA, using prefabricated, oligo(dT)-cellulose, chromatographic columns (Clontech; Palo Alto, Calif.). For DNA gel-blot analysis, fragments resulting from enzymatic digestion were fractionated by electrophoresis through $1 \%$ TAE-agarose gels, and fractionated DNAs were denatured as described by Sambrook et al. (1989). For RNA gel-blot analysis, RNAs were fractionated in formaldehyde-MOPS-agarose gels and subsequently were partially hydrolyzed by brief exposure to ultraviolet light. Nucleic acids were affixed to nylon membranes (Zeta-Probe; Bio-Rad; Hercules, Calif.) by capillary transfer and vacuum baking as described by Sambrook et al. (1989). DNA probes were radiolabed by random-hexadeoxynucleotide-primed, ${ }^{32} \mathrm{P}-\mathrm{dATP}$ incorporation using a commercially available kit (NEBlot Kit; New England Biolabs; Beverly, Mass.).

Nucleic acid probes used in gel-blot analyses were generated from the respective cloned cDNAs and are as follows: PcEXP1, a 524-bp fragment containing 104 bp of coding region and the entire 3' untranslated region, generated by PCR using the oligonucleotide primer EXP3F (5'..GGCTCTGTCTTTCCAAGTCA...3') and vector-specific primer T7; PcEXP2, a 415-bp fragment containing $140 \mathrm{bp}$ of coding region and the entire $3^{\prime}$ untranslated region, generated by PCR using the primers EXP5F (5'..GCAAAACTGGCAGAGCAACAC..3') and T7; PcEXP4, a 370-bp fragment containing $320 \mathrm{bp}$ of coding region and the entire 3' untranslated region, generated by PCR using the primers EXP12F (5'..GGATCAGGTTCACAATCAACG..3') and T7; PCEXP5, a 543-bp fragment consisting entirely of 3' untranslated region, generated by digestion of a $P c E X P 5$ cDNA clone with $X b a$ I and Xho I; PcPME1, a 542-bp fragment from the 3' end of the most extensive clone, generated by PCR using the primers PME1 (5'..GAACCCAAAGGGCT..3') and T7; and PcPME2, a 538-bp fragment containing the 3 ' end of the cDNA, generated by PCR using the primers PME2 (5'..CCGATTTGGCCTCAAGTAAC..3') and T7. Entire cDNAs were used as probes for PcPEL1 and PCXET1.

Blots were incubated in hybridization buffer $\left[0.25 \mathrm{M} \mathrm{Na}_{2} \mathrm{HPO}_{4}\right.$ (pH 7.4), $1 \mathrm{~mm}$ EDTA, $7 \% \operatorname{SDS}(\mathrm{w} / \mathrm{v})]$ for $30 \mathrm{~min}$ at $65^{\circ} \mathrm{C}$ before replacement by hybridization buffer containing denatured probe, and subsequent incubation for 8 to $16 \mathrm{~h}$ at $65^{\circ} \mathrm{C}$. Blots were washed for $1 \mathrm{~h}$ at $65^{\circ} \mathrm{C}$ using two changes of a low-salt wash [40 mu $\mathrm{NaHPO}_{4}$ (pH 6.8), 1 mm EDTA, $1 \%$ SDS (w/v)]. Blots were analyzed by phosphorimaging.

CDNA library CONSTRUCTION. CDNAs were synthesized from poly $(\mathrm{A})^{+}$RNA using poly(dT) oligonucleotide primers and reverse transcriptase (Superscript II; Gibco-BRL; Grand Island, N.Y.). DNA libraries were constructed in the Uni-ZAP XR vector (Stratagene; La Jolla, Calif.) using size-selected cDNAs according to manufacturer's instructions. Two libraries were used for this study, both derived from fruit RNAs expressed during the later stages of ripening [53 days postanthesis (DPA)]. Library RF-A contained 0.5 to $3 \mathrm{~kb}$ cDNAs; library RF-B contained 1.5 to $8 \mathrm{~kb}$ cDNAs. Initial titers indicated that the libraries represented at least $2 \times 10^{6}$ recombinants.

Cloning of expansin Genes. For cloning of full-length expansin genes, degenerate primers were used to amplify expansin sequences from $50 \mathrm{ng}$ RF cDNA using primers and conditions as described by Brummell et al. (1999b). Completed PCR reactions were radiolabeled as described above and used directly as a probe to screen $\approx 2 \times 10^{6}$ recombinant phage from the RF-A and RF-B cDNA libraries. Library screening was done as described in Sambrook et al. (1989). Twenty phage species hybridizing with the probe were isolated, converted to phagemids, and cDNAs were subjected to single-pass sequencing from the 5' end. The most extensive clone corresponding to each expansin gene was sequenced in its entirety on both strands.

IDENTIFICATION OF RIPENING-ASSOCIATED GENES. For identification of genes that were upregulated at early stages of ripening, DNA from randomly selected cDNA clones derived from the primary libraries was prepared and arrayed in duplicate onto replicated, $11 \times 7.5$-cm nylon membranes using a BioMek 2000 robotic workstation (Beckman Instruments, Fullerton, Calif.). Replicate membranes were hybridized with radiolabeled total cDNA derived from fruit collected at 35 or 45 DPA, and hybridization was quantified using phosphorimaging and ImageQuant software (Amersham; Sunnyvale, Calif.). Those clones that showed a $10 \%$ or greater increase in hybridization with cDNA from 45 DPA fruit, relative to 35 DPA fruit, were subjected to single-pass sequencing from the 5' end.

DNA AND PROTEIN SEQUENCE ANALYSIS. Sequencing utilized the AmpliCycle Sequencing Kit (Perkin-Elmer Corp.; Norwalk, Conn.) in combination with an automated DNA sequencer(PRISM model 377; Applied Biosystems; Foster City, Calif.). The nucleotide sequence data for the cherry cDNAs reported here are cataloged in the EMBL and GenBank Nucleotide Sequence Databases under the accession numbers AF350936 (PcEXP1), AF350937 (PcEXP2), AF350939 (PcEXP4), AF448467 (PcEXP5), BG319625 (PcPEL1), BG319624 (PcPME1), BM083971 (PcPME2), and BG319626 (PcXET1). Database searches were carried out using BLASTX with databases and software maintained by the National Center for Biotechnology Information (NCBI). Presence of functional domains common to known carbohydrate-modifying enzymes was determined in conjunction with the Carbohydrate-Active Enzyme Server (http:// afmb.cnrs-mrs.fr/CAZY/index.html) maintained by the Centre National de la Recherche Scientifique, Université de Provence. Other sequence analyses were carried out using programs of the Genetics Computer Group (Madison, Wis.) software package (Devereux et al., 1984). SPScan was used for identification of secretory signal peptides in predicted peptide sequences. This program utilizes the weight matrix method of von Heijne (1986). PILEUP was used for sequence comparisons.

For phylogenetic analyses of expansin proteins, a majorityrule consensus tree (neighbor-joining/bootstrap replicates $=100$ ) was built using PAUPsearch. Mature protein sequence was derived from database accessions when necessary using SPScan. Database accession numbers for sequences used for comparisons are as follows: LeEXP1, U82123; LeEXP2, AF096776; LeEXP3, AF059487; LeEXP4, AF059488; LeEXP5, AF059489; LeEXP8, AF184232; LeEXP9, AJ243340; LeEXP10, AF184233; LeEXP18, AF004997; FaEXP2, AF159563. 


\section{Results and Discussion}

Cherry growth AND Changes IN CELL WALL Weight. Similar to other stone fruit, $P$. cerasus fruit exhibits a biphasic growth pattern (Fig. 1a). An initial, brief period of very rapid growth immediately follows $\mathrm{a} \approx 10 \mathrm{~d}$ postpollination period of cell proliferation and differentiation (Tukey, 1935). Subsequently, following a period of 15 to $20 \mathrm{~d}$, during which the fruit exhibits only slight enlargement and the stony endocarp (pit) undergoes hardening, a second period of moderate growth occurs (Fig. 1a). This second growth phase is initiated synchronously with tissue softening and other ripening processes, such as accumulation of soluble sugars and development of color (Tukey, 1935).

To better understand the relationship between firmness and cell wall dynamics, we analyzed changes in cell wall weight during development of the fruit. Early in fruit development, the weight of cell wall materials measured on a per-fruit basis increased rapidly, approximately doubling between 16 and 36 DPA (Fig. 1b). This increase was associated with the initial growth phase of the fruit and subsequent pit hardening. In contrast, between $36 \mathrm{DPA}$ and $42 \mathrm{DPA}$, corresponding to the earliest stages of the second growth phase and softening, cell wall weight declined sharply, reaching a level similar to that seen in fruit 16 DPA. Following 42 DPA, cell wall weight remained largely unchanged (Fig. 1B), even though fruit size and total weight continued to increase. These findings suggest that major changes in cell wall architecture take place at the initiation of ripening in cherry. However, softening continued in parallel with moderate growth of the fruit through 59 DPA (Fig. 1A and data not shown), suggesting that the wall was being continuously modified throughout this period.

IDENTIFICATION AND CLONING OF EXPANSIN GENES. As a first step to explore a potential role for expansins in ripening-associated cell wall modification in sour cherry, we characterized expansin genes expressed in ripe (53 DPA) fruit. Degenerate primers were used to amplify expansin-like sequences from pericarp tissues, and these sequences were used to screen a cDNA library prepared from the same tissues. This approach resulted in the identification of four distinct gene sequences that we designated $P c E X P 1$, PcEXP2, PcEXP4, and PcEXP5 (Table 1). The most extensive cDNA clone corresponding to each gene was sequenced in its entirety. Conceptual translation of the PcEXP cDNAs revealed that the RNAs would encode proteins that share 59\% to $69 \%$ amino acid sequence identity, and that show strong sequence homology to an expansin from cucumber, designated S1, for which expansin activity has been demonstrated in transgenic plants (Rochange and McQueen-Mason, 2000) (Table 1). Also, the predicted proteins exhibit features that are conserved among known a-expansins, including a characteristic pattern of eight cysteine and four tryptophan residues that presumably play a role in binding of expansins to their carbohydrate target(s) (Shcherban et al., 1995) (data not shown). Expansins and other cell walllocalized proteins typically contain signal peptides that direct the protein into the secretory pathway. Analysis of these cherry expansins for secretory signal sequences using the rules of von Heijne (1986) suggested the presence in each protein of a short, amino-terminal signal sequence (data not shown).

Gel blotting of genomic DNA using probes corresponding predominantly to the $3^{\prime}$ untranslated regions of the cDNAs detected only a single, strongly hybridizing DNA fragment for at least one of the restriction enzymes used (Fig. 2), suggesting that each of the four genes exists as a single copy in cherry. However, in some cases, other weakly hybridizing fragments were apparent, suggesting that related genes exist (Fig. 2).

EXPRESSION OF EXPANSIN RNAS DURING FRUIT DEVELOPMENT. RNAs hybridizing with all four expansin gene probes were very strongly upregulated at the onset of the second growth phase and softening (between 35 and 40 DPA, Fig. 3A). RNAs detected by $P c E X P 1,2$, and 5 maintained a high level of expression throughout the ripening phase, whereas those hybridizing with PcEXP4 decreased in ripe fruit (Fig. 3A). In addition, weak hybridization with $P c E X P 1$ and 4 was evident during the phase of rapid growth following pollination (15 DPA) and with PcEXP1 and 5 during the pit hardening phase (30 DPA) (Fig. 3A). There was no significant cross-hybridization among the four PcEXP cDNAs analyzed (Fig. 3B), indicating that these probes were probably specific for each gene under the hybridization conditions used.

The induction of RNA expression of the four PcEXP genes at the advent of the ripening phase is analogous to that reported for expansins from tomato [LeEXP1 (Brummell et al., 1999b; Rose et al., 1997)] and strawberry [FaEXP2 (Civello et al., 1999)]. The absence of strong RNA expression of the four PcEXP genes at early stages of fruit development suggests that these expansins are probably not important for the cell expansion that accompanies early growth of cherries. The weak hybridization observed at
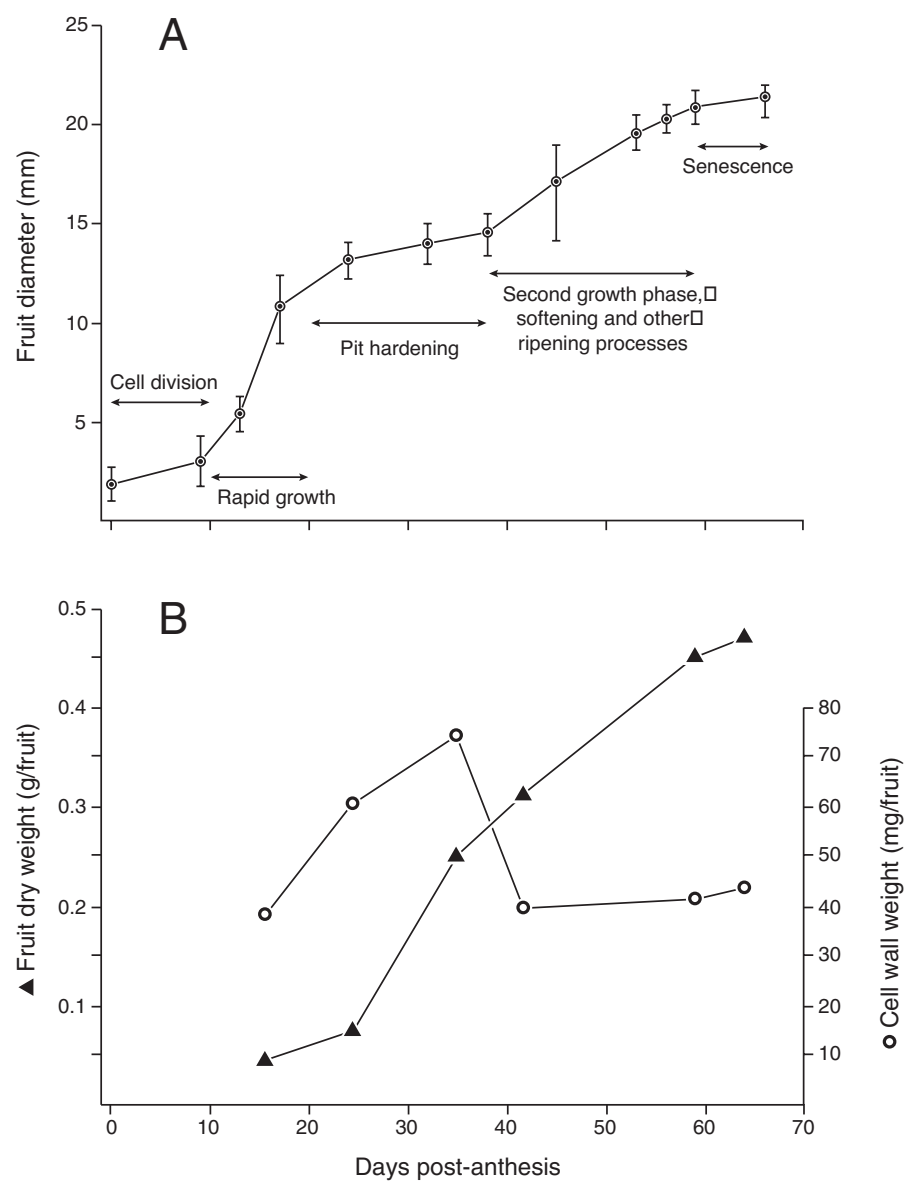

Fig. 1. Growth and development of sour cherries during one growing season. (A) Growth and extent of major developmental stages. Flowers were tagged at anthesis, and the maximum diameter of tagged fruit was determined periodically until abscission. Values indicate the mean and range of measurements for 10 fruit. (B) Changes in total dry weight and cell wall weight (weight of lyophilized materials following phenol-acetic acid extraction). Pits were removed prior to analysis. Values indicate the mean for 12 to 20 fruit. This analysis was repeated with a second sample of fruit, with similar results. 
Table 1. Characterization of cDNA sequences reported in this study.

\begin{tabular}{lccc}
\hline \hline Gene & cDNAs $^{\mathrm{z}}$ & Length $^{\mathrm{y}}$ & Blastx match $^{\mathrm{x}}$ \\
\hline PcEXP1 & 3 & 1233 & Cucumber expansin S1 (T10079) $^{\mathrm{w}}$ \\
PcEXP2 & 5 & 1109 & Cucumber expansin S1 (T10079) \\
P EXP4 & 1 & 965 & Cucumber expansin S1 (T10079) \\
PcEXP5 & 11 & 1419 & Cucumber expansin S1 (T10079) \\
$P c P M E 1$ & 4 & 1359 & Tomato PME2 (Q96575) \\
$P c P M E 2$ & 1 & 626 & Tomato PME2 (Q96575) \\
$P c P E L 1$ & 4 & 1242 & Zinnia ZePEL (Y09541) \\
$P c X E T 1$ & 10 & 844 & Nasturtium XET (S48102)
\end{tabular}

${ }^{2}$ Total number of cDNAs identified by library screening (expansins) or array hybridization.

yTotal length of cDNA or assembled contig (bp).

'Indicates most homologous protein of defined activity.

windicates the probability that sequence match occurred by chance.

these stages could reflect weak activity of these genes, or may simply be due to cross-hybridization with strongly expressed, related genes. In this respect, we note that distinct expansins are expressed during early fruit growth in tomato (Brummell et al., 1999b).

Phylogenetic Relationships Among EXPansins eXPResSed in DEVELOPING FRUIT. Based on phylogenetic analysis of known expansin peptide sequences, Rose et al. (1997) suggested that expansins expressed in ripening fruit defined a structurally related subgroup of expansins. However, in a subsequent study with tomato, Brummell et al. (1999b) noted a relatively strong relationship between the sequence of LeEXP1, an expansin expressed in ripening fruit, and that of another expansin, $L e$ EXP4, which is expressed only in young, green fruit. In addition, Civello et al. (1999) noted that an expansin expressed in ripening strawberry, $F a \mathrm{EXP} 2$, did not exhibit a particularly close relationship to LeEXP1. We examined the phylogenetic relationships among $P c \mathrm{EXP} 1,2$, 4, and 5, FaEXP2, and nine expansins currently identified in tomato (Fig. 4). Our results indicate that $P c$ EXP1 and $P c$ EXP2 are members of a weakly defined clade including $F a \mathrm{EXP} 2$ and a tomato expansin, $L e \mathrm{EXP} 2$, whose RNA is expressed early in development, when the fruit is growing rapidly (Català et al. 2000). PcEXP5 fell into a separate clade containing the tomato $L e \mathrm{EXP} 5$, whose RNA accumulates in a pattern similar to that of $L e \mathrm{EXP} 2$, and $L e \mathrm{EXP} 10$, whose RNA expression pattern has not been reported. $P c \mathrm{EXP} 4$ fell into a clade including $L e \mathrm{EXP} 1$, but also including LeEXP4 and two other tomato expansins of undefined expression pattern, $L e$ EXP18 and $L e$ EXP9. Although these results are inconsistent with the idea set forward by Rose et al. (1997) that ripening-related expansins comprise a structurally-related subgroup of expansins, expansins closely related in structure could define subclasses with related biochemical activity (e.g., preference for specific carbohydrate structures, or activity in similar physio-chemical environments). Interestingly, both PcEXPI and PcEXP2 were also strongly expressed in the fruitpedicel abscission zone during its rapid dissolution late in ripening (data not shown), suggesting that the biochemical activity of these expansins is not specific to ripening fruit.

IDENTIFICATIONANDEXPRESSION ANALYSIS OF OTHER CELL WALL MODIFYING GENES ASSOCIATED WITH FRUIT RIPENING. Based on the persistence of large pectin polymers late in the ripening of LeEXP 1-suppressed tomato fruit, Brummell et al. (1999a) suggested that expansins act in fruit softening not only by directly mediating wall relaxation, but also indirectly, by limiting access of pectinase(s) to their substrates. They also suggested that expansins may function in concert with hemicellulose-modifying enzymes, as expansin overexpression in transgenic tomato leads to precocious depolymerization of hemicelluloses. To identify specific genes involved in pectin or xyloglucan modification that might function in the early stages of ripening, we used a cDNAarray hybridization approach (see Materials and Methods) to identify genes that were potentially upregulated at the onset of the second growth phase and softening. The nucleotide sequences of genes that exhibited potential upregulation were assembled into overlapping, contiguous sequences (contigs), and the contig sequences were analyzed both for presence of derived functional domains common to known classes of carbohydrate-modifying enzymes, as defined by Coutinho and Henrissat (1999), and for sequence homology with genes encoding known pectin and hemicellulose-modifying enzymes. The expression pattern of genes that were identified in this manner was analyzed by RNA gel blotting, using conditions under which hybridization to related gene family members was expected (see Materials and Methods).

Fig. 2. Genomic organization of the PcEXP1, 2, 4, and 5 genes. P. cerasus genomic DNA was analyzed by gel blotting using probes as described in Materials and Methods. Restriction enzymes used in the analysis are indicated: $B c, B c l$ I; Ba, Bam HI; P, Pst I; N, Nde I. Migration positions of DNA size markers are shown.

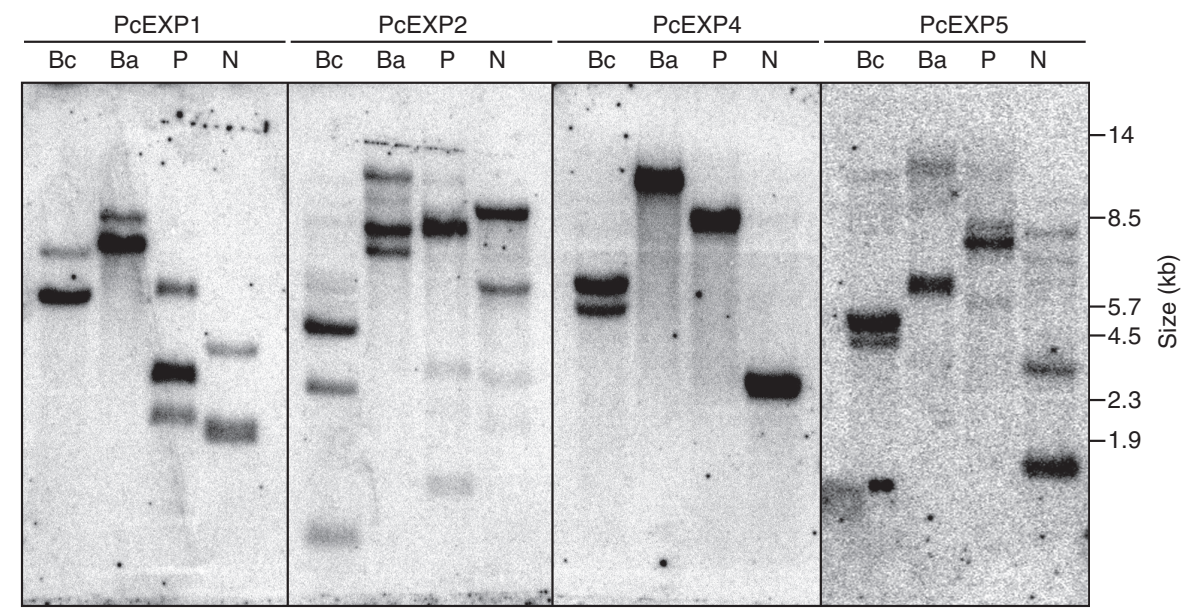


A

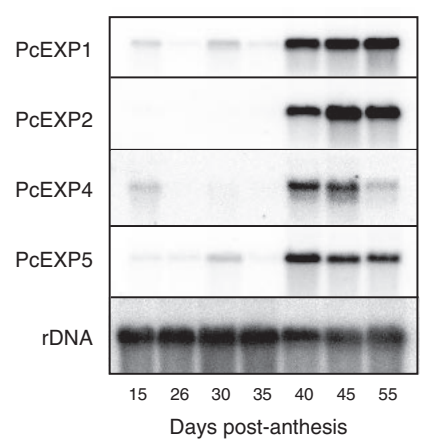

Fig. 3. Expression of $P c E X P 1,2,4$, and 5 RNAs during fruit development. (A) RNA was extracted from developing fruit, and analyzed by gel blotting. An $18 \mathrm{~s}$ rDNA probe was used to indicate amount of total RNA present in each lane. (B) Hybridization of probes used in A to PcEXP1,2,4, and 5 cDNAs was analyzed by dot blotting to demonstrate specificity of the probes.

A cluster of four, partially overlapping cDNA clones and one distinct cDNA were identified that defined two members of carbohydrate esterase family 8 (pectin methylesterases; EC 3.1.1.11), and these were designated PcPME1 and PcPME2 (Table 1). Within the sequenced regions, these cDNAs shared $55 \%$ to $65 \%$ sequence identity. Both would encode proteins highly related to a known PME from tomato, PME2 (Tieman and Handa, 1994) (Table 1). Comparison with the tomato protein suggested that the collective PcPMEl cDNAs represented the full length of the RNA (data not shown). RNAs hybridizing with a PcPME1 probe were detectable at all stages of development, and exhibited strong upregulation between 35 and 40 DPA (Fig. 5). RNAs hybridizing with the $P c P M E 2$ probe were detectable only after 15 DPA, and were also strongly upregulated between 35 and 40 DPA (Fig. 5). Although it is known that PME activity increases during the course of fruit development and ripening in several species (Brummell and Harpster, 2001), this is the first report of such strong, ripening-associated upregulation of $P M E$ like genes.

We identified a cluster of four, partially overlapping cDNAs representing a cherry gene designated PCPEL1, that would encode a member of the pectin/pectate lyase family (EC 4.2.2.10 and EC 4.2.2.2, respectively) (Table 1). This protein would exhibit strong homology with a Zinnea protein, ZePEL, that exhibits pectate lyase activity in vitro (Domingo et al., 1998) (Table 1). RNAs hybridizing with the PcPEL1 cDNA were strongly upregulated at the initiation of ripening (between 35 and 40 DPA) and were abundant thereafter (Fig. 5). Weakly-hybridizing RNAs were also detected at 15 DPA, during the first period of rapid fruit growth.

Pectate lyases are most commonly known as virulence factors secreted by bacterial pathogens that cause soft-rot symptoms (Herron et al., 2000). Ripening-associated induction of $P E L$-like genes has previously been demonstrated in banana (Musa acuminata Coll.) (Dominguez-Puigjaner et al., 1997) and strawberry (Medina-Escobar et al., 1997). In conjunction with the demonstration that antisense suppression of a strawberry PELlike gene increases fruit firmness (Jiménez-Bermúdez et al., 2002), our results are consistent with the hypothesis that PELs play major roles in tissue softening, at least in some fruit.

We also identified a cluster of 10 , partially overlapping cDNAs representing a member of glycoside hydrolase family 16 . This family is polyspecific and includes at least seven different activities, including xyloglucan endotransglycosylase (XET) (EC 2.4.1.207) (Coutinho and Henrissat, 1999). The predicted protein exhibited very high homology ( $80 \%$ sequence identity $/ 92 \%$ similarity) with a biochemically characterized XET from Nasturtium (de Silva et al., 1993), throughout the entire length of the Nasturtium protein, suggesting that the cherry protein is an XET (Table 1 and data not shown). RNA gel blot analysis of developing fruit, using an entire PcXETI cDNA as a probe, detected RNAs that were strongly upregulated between 35 and 40 DPA and strongly expressed thereafter (Fig. 5).

Ripening-associated induction of an XET gene has previously been demonstrated in kiwifruit (Actinidia deliciosa A. Chev.) (Schroder et al., 1998). Biochemical characterization of the kiwifruit XET indicated that it was capable of either strictly hydrolytic or endotransglycosylase activity, depending on the availability of nonreducing xyloglucan end groups (Schroder et al., 1998). The endoglycosylase activity resulted in a net decrease in xyloglucan size when acceptor xyloglucans were small (Schroder et al., 1998). Depolymerization of tightly-bound xyloglucan occurs as an early step in ripening in many fruit (Rose et al., 1998; Tong and Gross, 1988). The enzymatic activity that may mediate this depolymerization has not been positively identified, but the ripening-associated induction of the kiwifruit XET and of $P C X E T 1$ suggests that these proteins could function in this role.

About 245 of the 752 cDNAs analyzed by array hybridization showed potential upregulation in ripening fruit, and sequence

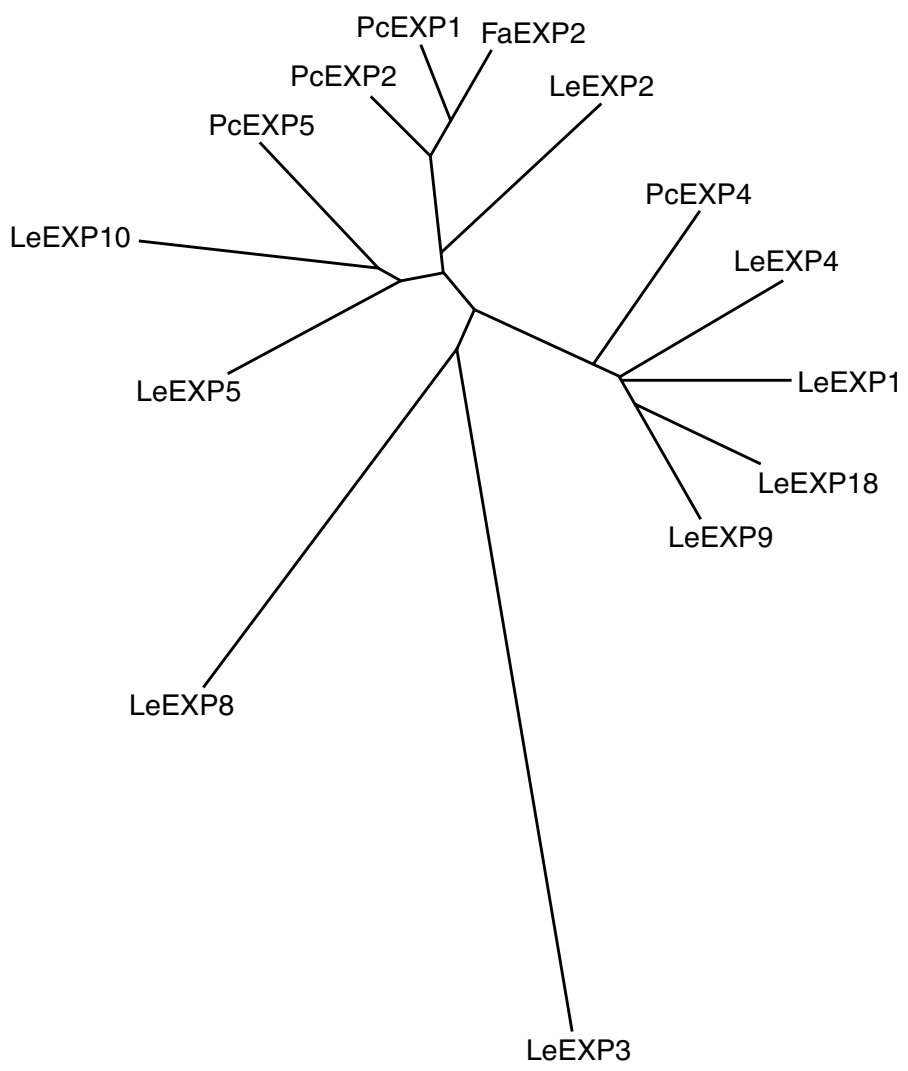

Fig. 4. Phylogenetic relationships among $P c \mathrm{EXP} 1,2,4$, and 5 from cherry and expansins from tomato ( $L e$ EXPs) and from strawberry ( $F a$ EXP2). Phylogenetic trees were constructed using deduced mature amino acid sequences. A representative tree is shown. For details of the analysis and gene accession numbers, see Materials and Methods. 


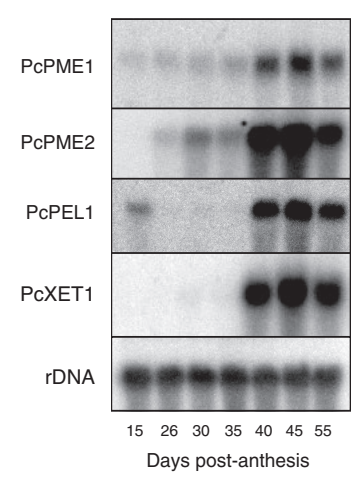

Fig. 5. Expression pattern of RNAs encoding proteins potentially involved in cell wall modification during fruit development. RNA was extracted from developing fruit and analyzed by gel blotting. Probes are described in Materials and Methods. An 18s rDNA probe was used to indicate the amount of total RNA present in each lane.

analysis indicated that these cDNAs represented 120 distinct genes (data not shown). Although results from this type of technique typically need confirmation through RNA gel blotting, this finding suggests that the initiation of ripening in sour cherry involves extensive changes in gene expression. Whereas $P c E X P 1,2$, and 5 were identified by this approach, $P c E X P 4$ was not, and this demonstrates the limitations of this technique. We did not identify genes encoding potential glycosylases, PGs or B-1,4-glucanases. This does not necessarily exclude a role for these genes in cherry softening, as they may not have been represented on our cDNA array. Alternatively, they may not be upregulated at this stage of cherry development, could be expressed at much lower levels, or their activity could be regulated at the protein level.

Our results suggest that numerous activities-including expansin, PME, PEL, and XET, could be involved in ripeningassociated cell wall modification in sour cherry. For the most part, previous biotechnological approaches to affect fruit softening have targeted individual enzymes. However, compositional studies, and molecular studies such as this, have now clearly shown that fruit softening could be a complex process, potentially moderated by multiple and diverse activities. Thus, significant control of this process through biotechnological approaches may require the targeting of multiple genes, potentially through manipulation of 'upstream' regulatory factors.

An intriguing question is the identity of the factor(s) that may coordinate the ripening-related expression of these genes. Although this role is largely moderated through ethylene signaling in many fruit, no ethylene-associated climacteric peak occurs during ripening in cherry, and ripening of this fruit is not strongly affected by exogenous ethylene (Li et al., 1994). Auxin apparently has a prominent role as a repressor of the initiation of ripening in at least some nonclimacteric fruit, including strawberry, where removal of the auxin-producing achenes in young fruit leads to precocious ripening and expression of ripeningrelated genes (Given et al., 1988, Manning, 1998), and in both strawberry and grape (Vitis vinifera L.), where application of auxin delays ripening and the upregulation of many ripeningrelated genes (Davies et al., 1997; Manning, 1998). In cherry there is no strong correlation between fruit development and auxin levels in either seed or pericarp tissues (Hopping and Bukovac, 1975), suggesting that still other signals could be important in initiating ripening in this species. Some insight into the nature of the control of ripening in nonclimacteric fruit may come from the identification and characterization of cis-acting elements in the regulatory regions of the ripening-related genes identified in this study, and the use of these genes as reporters in transgenic plants.

\section{Literature Cited}

Brownleader, M.D., P. Jackson, A. Mobasheri, A.T. Pantelides, S. Sumar, M. Trevan, and P.M. Dey. 1999. Molecular aspects of cell wall modifications during fruit ripening. Crit. Rev. Food Sci. Nutr. 39:149_ 164.

Brummell, A.D. 1999. Antisense suppression of tomato endo-1,4-ß3glucanase Cel2 mRNA accumulation increases the force required to break fruit abscission zones but does not affect fruit softening. Plant Mol. Biol. 40:615-622.

Brummell, A.D. and M.H. Harpster. 2001. Cell wall metabolism in fruit softening and quality and its manipulation in transgenic plants. Plant Mol. Biol. 47:311-340.

Brummell, A.D., M.H. Harpster, P.M. Civello, J.M. Palys, A.B. Bennett, and P. Dunsmuir. 1999a. Modification of expansin protein abundance in tomato fruit alters softening and cell wall polymer metabolism during ripening. Plant Cell 11:2203-2216.

Brummell, A.D., M.H. Harpster, and P. Dunsmuir. 1999b. Differential expression of expansin gene family members during growth and ripening of tomato fruit. Plant Mol. Biol. 39:161-169.

Brummell, A.D. and J.M. Labavitch. 1997. Effect of antisense suppression of endopolygalacturonase activity on polyuronide molecular weight in ripening tomato fruit and in fruit homogenates. Plant Physiol. 115:717-725.

Català, C., J.K.C. Rose, and A.B. Bennett. 2000. Auxin-regulated genes encoding cell wall-modifying proteins are expressed during early tomato fruit growth. Plant Physiol. 122:527-534.

Civello, P.M., A.L.T. Powell, A. Sabehat, and A.B. Bennett. 1999. An expansin gene expressed in ripening strawberry fruit. Plant Physiol. 121:1273-1279.

Cosgrove, D.J. 1998. Cell wall loosening by expansins. Plant Physiol. 118:333-339

Coutinho, P.M. and B. Henrissat. 1999. Carbohydrate-active enzymes: an integrated database approach, p. 3-12. In: H.J. Gilbert, G. Davies, B. Henrissat, and B. Svensson (eds.). Recent advances in carbohydrate bioengineering. Royal Soc. Chem., Cambridge.

Davies, C., P.K. Boss, and S.P. Robinson. 1997. Treatment of grape berries, a nonclimacteric fruit, with a synthetic auxin, retards ripening and alters the expression of developmentally regulated genes. Plant Physiol. 115:1155-1161.

de Silva J., C.D. Jarman, D.A. Arrowsmith, M.S. Stronach, S. Chengappa, C. Sidebottom, and J.S. Reid. 1993. Molecular characterization of a xyloglucan-specific endo-(1-4)-beta-D-glucanase (xyloglucan endotransglycosylase) from Nasturtium seeds. Plant J. 3:701-711.

Devereux, J., P. Haeberli, and O. Smithies. 1984. A comprehensive set of sequence analysis programs for the VAX. Nucleic Acids Res. 12:387-395.

Domingo, C., K. Roberts, N.J. Stacey, I. Connerton, F. Ruiz-Teran, and M.C. McCann. 1998. A pectate lyase from Zinnia elegans is auxin inducible. Plant J. 13:17-28.

Dominguez-Puigjaner, E., I. Llop, M. Vendrell, and S. Prat. 1997. A cDNA clone highly expressed in ripe banana fruit shows homology to pectate lyases. Plant Physiol. 114:1071-1076.

Doyle, J.J. and J.L. Doyle. 1990. Isolation of plant DNA from fresh tissue. Focus 12:13-15.

Giovannoni, J.J., D. DellaPenna, A.B. Bennett, and R.L. Fischer. 1989 Expression of a chimeric polygalacturonase gene in transgenic rin (ripening inhibitor) tomato fruit results in polyuronide degradation but not fruit softening. Plant Cell 1:53-63.

Given, N.K., M.A. Venis, and D. Grierson. 1988. Hormonal regulation of ripening in the strawberry, a non-climacteric fruit. Planta 174:402_ 406.

Hall, L.N., G.A. Tucker, C.J.S. Smith, C.F. Watson, G.B. Seymour, Y. Bundick, and J.M. Boniwell. 1993. Antisense inhibition of pectin esterase gene expression in transgenic tomatoes. Plant J. 3:121-129.

Herron, S.R., J.A. Benen, R.D. Scavetta, J. Visser, and F. Jurnak. 2000. Structure and function of pectic enzymes: Virulence factors of plant pathogens. Proc. Natl. Acad. Sci. USA 97:8762-8769.

Hopping, M.E. and M.J. Bukovac. 1975. Endogenous plant growth substances in developing fruit of Prunus cerasus L. IV. Extractable auxin in the seed and pericarp. J. Amer. Soc. Hort. Sci. 100:399-401. Hunter, D.A. and M.S. Reid. 2001. A simple and rapid method for isolating 
high quality RNA from flower petals. Acta Hort. 543:147-152.

Jiménez-Bermúdez, S., J. Redondo-Nevado, J. Muñoz-Blanco, J.L. Caballero, J.M. López-Aranda, V. Valpuesta, F. Pliego-Alfaro, M.A. Quesada, and J.A. Mercado. 2002. Manipulation of strawberry fruit softening by antisense expression of a pectate lyase gene. Plant Physiol. 128:751759.

Lashbrook, C.C., J.J. Giovannoni, B.D. Hall, R.L. Fischer, and A.B. Bennett. 1998. Transgenic analysis of tomato endo- $\beta-1,4$-glucanse gene function. Role of cell in floral abscission. Plant J. 13:303-310.

Li, S., P.K. Andrews, and M.E. Patterson. 1994. Effects of ethephon on the respiration and ethylene evolution of sweet cherry (Prunus avium L.) fruit at different development stages. Postharvest Biol. Technol. 4:235-243.

Manning, K. 1998. Isolation of a set of ripening-related genes from strawberry: Their identification and possible relationship to fruit quality traits. Planta 205:622-631.

McQueen-Mason, S.J. and D.J. Cosgrove. 1995. Expansin mode of action on cell walls. Analysis of wall hydrolysis, stress relaxation, and binding. Plant Physiol. 107:87-100.

Medina-Escobar, N., J. Cardenas, E. Moyano, J.L. Caballero, and J. Munoz-Blanco. 1997. Cloning, molecular characterization and expression pattern of a strawberry ripening-specific cDNA with sequence homology to pectate lyase from higher plants. Plant Mol. Biol. 34:867877.

Rochange, S.F. and S.J. McQueen-Mason. 2000. Expression of a heterologous expansin in transgenic tomato plants. Planta 211:583-586.

Rose, J.K.C., K.A. Hadfield, J.M. Labavitch, and A.B. Bennett. 1998.
Temporal sequence of cell wall disassembly in rapidly ripening melon fruit. Plant Physiol. 117:345-361.

Rose, J.K.C., H.H. Lee, and A.B. Bennett. 1997. Expression of a divergent expansin gene is fruit-specific and ripening-regulated. Proc. Natl. Acad. Sci. USA 94:5955-5960.

Sambrook, J., E.J. Fritsch, and T. Maniatis. 1989. Molecular cloning: A laboratory manual. Cold Spring Harbor Laboratory Press, Cold Spring Harbor, N.Y.

Schröder, R., R.G. Atkinson, G. Langenkämper, and R.J. Redgwell. 1998. Biochemical and molecular characterisation of xyloglucan endotransglycosylase from ripe kiwifruit. Planta 204:242-251.

Shcherban, T.Y., J. Shi, D.M. Durachki, M.J. Guiltinana, S.J. McQueenMason, M. Shieh, and D.J. Cosgrove. 1995. Molecular cloning and sequence analysis of expansins - A highly conserved, multigene family of proteins that mediate cell wall extension in plants. Proc. Natl. Acad. Sci. USA 92:9245-9249.

Tieman, D.M. and A.K. Handa. 1994. Reduction in pectin methylesterase activity modifies tissue integrity and cation levels in ripening tomato (Lycopersicon esculentum Mill.) fruits. Plant Physiol. 106:429-436.

Tong, C.B.S. and K.C. Gross. 1988. Glycosyl-linkage composition of tomato fruit cell wall hemicellulose fractions during ripening. Physiol. Plant. 74:365-370.

Tukey, H.B. 1935. Growth of the embryo, seed, and pericarp of the sour cherry (Prunus cerasus) in relation to season of fruit ripening. Proc. Amer. Soc. Hort. Sci. 31:125-144.

von Heijne, G. 1986. A new method for predicting signal sequence cleavage sites. Nucleic Acids Res. 14:4683-4690. 